\title{
Orofacial myofunctional disorder, a possible complicating factor in the management of painful temporomandibular disorder. Case report
}

\author{
Distúrbio miofuncional orofacial, um possível fator complicador no manuseio da disfunção \\ temporomandibular dolorosa. Relato de caso
}

Melissa de Oliveira Melchior ${ }^{1}$, Laís Valencise Magri' ${ }^{1}$, Marcelo Oliveira Mazzetto ${ }^{1}$

DOI 10.5935/2595-0118.20180017

\section{ABSTRACT}

BACKGROUND AND OBJECTIVES: The clinical association between painful temporomandibular disorder and orofacial myofunctional disorders is frequent and requires attention. The objective of this study was to describe a clinical case of painful temporomandibular disorder in association with orofacial myofunctional disorders that evidence the importance of dental and speech therapy approaches involving myofunctional orofacial limits, as well as to discuss whether the presence of orofacial myofunctional disorders can be a comorbidity that hinders the temporomandibular disorder management.

CASE REPORT: Female patient, 35 years old, complaining of pain in the orofacial region and joint noises during high amplitude mandibular movements for 17 years. She was diagnosed with myofascial pain and arthralgia (RDC/TMD) and orofacial myofunctional disorders (phonoarticulation with deviations and lingual interposition, atypical swallowing, oromandibular incoordination and mandibular hyperexcursion with eminence noise). Complementary tests (electromyography and electrovibratography) were performed in the pre- and post-treatment moments (1 year after). The treatment consisted of self-management and mindfulness orientations, stabilizing occlusal splint and speech therapy. After the treatment, there was an improvement in pain and mandibular range of motion, with consequent reduction of noise, better electromyographic balance and reduction of orofacial myofunctional disorders scores.

CONCLUSION: The case report has suggested that the presence of orofacial myofunctional disorders in association with painful temporomandibular disorder could interfere in the management of pain and the balance of the stomatognathic system because it seems to act as a worsening factor to the temporomandibular

1. Universidade de São Paulo, Faculdade de Odontologia de Ribeirão Preto, Departamento de Odontologia Restauradora, Área de Oclusão, Disfunção Temporomandibular e Dor Orofacial, Ribeirão Preto, SP, Brasil.

Submitted in October 25, 2017.

Accepted for publication in January 29, 2018.

Conflict of interests: none - Sponsoring sources: none

Correspondence to:

Avenida do Café, s/n, Monte Alegre

Faculdade de Odontologia

14040-904 Ribeirăo Preto, SP, Brasil.

E-mail: laisvmagri@gmail.com

(C) Sociedade Brasileira para o Estudo da Dor disorder signs and symptoms. In this sense, the importance of dental and speech therapy interventions in patients with orofacial myofunctional disorders as possible comorbidity to painful temporomandibular disorder is highlighted.

Keywords: Comorbidity, Speech therapy, Temporomandibular joint dysfunction syndrome.

\section{RESUMO}

JUSTIFICATIVA E OBJETIVOS: A associação clínica da disfunção temporomandibular dolorosa com distúrbios miofuncionais orofaciais é bastante frequente e requer atençáo. O objetivo deste estudo foi mostrar um caso de disfunçáo temporomandibular dolorosa com associação de distúrbios miofuncionais orofaciais que evidenciou a importância do manuseio terapêutico odontológico e fonoaudiológico, com abordagens que envolveram limites miofuncionais orofaciais, bem como discutir se a presença de distúrbios miofuncionais orofaciais pode ser uma comorbidade que dificulta o manuseio da disfunção temporomandibular.

RELATO DO CASO: Paciente do sexo feminino, 35 anos, com queixa de dor na regiáo orofacial e ruídos articulares durante movimentos mandibulares de grande amplitude há 17 anos. Diagnosticada com dor miofascial e artralgia (RDC/TMD) e distúrbios miofuncionais orofaciais (fonoarticulação com desvios e interposição lingual, deglutição atípica, descoordenação oromandibular e hiperexcursáo mandibular com ruído de eminência). Foram realizados exames complementares (eletromiografia e eletrovibratografia) nos momentos pré e pós-tratamento ( 1 ano após). O tratamento consistiu de orientaçóes de automanuseio e de atençáo plena nas funçôes orofaciais (mindfulness), placa oclusal estabilizadora e terapia fonoaudiológica. Após o tratamento, houve melhora da dor e da amplitude dos movimentos mandibulares, com consequente redução dos ruídos, maior equilíbrio eletromiográfico dos músculos e reduçáo dos escores dos distúrbios miofuncionais orofaciais.

CONCLUSÁO: O presente caso sugere que a presença dos distúrbios miofuncionais orofaciais em associação com a disfunção temporomandibular dolorosa pode interferir no manuseio da dor e no equilíbrio do sistema estomatognático, pois parece atuar como fator de piora dos sinais e sintomas da disfunçáo temporomandibular. Neste sentido, ressalta-se a importância de intervençóes odontológicas e fonoaudiológicas em pacientes que apresentem os distúrbios miofuncionais orofaciais como possível comorbidade à disfunção temporomandibular dolorosa.

Descritores: Comorbidade, Fonoaudiologia, Síndrome da disfunção da articulação temporomandibular. 


\section{INTRODUCTION}

Currently, temporomandibular dysfunctions (TMD) are defined as a set of signs and symptoms that indicate a painful musculoskeletal syndrome associated to multisystemic changes, as well as changes in behavior, in the emotional state and social interactions, recognized as manifestations of deregulation of the central nervous system ${ }^{1-3}$. Among the key predictors for the development of TMD is the presence of comorbidities, non-painful orofacial symptoms (such as self-report of parafunctions), the frequency of somatic symptoms, poor sleep quality, and genetic and epigenetic factors ${ }^{1,2}$. The most common signs and symptoms are the orofacial pain, joint noises and changes in jaw mobility ${ }^{4}$. The presence of comorbidities associated with painful TMD makes the diagnosis and management difficult, in special in the presence of other dysfunctional syndromes, such as headaches, fibromyalgia, and cervicalgia ${ }^{5,6}$. These comorbidities can be a huge challenge in specific clinical cases since the physiopathological mechanisms, and the site of pain involvement or perception can be very similar to the $\mathrm{TMD}^{6}$. The central sensitization, the involvement of the pain descending inhibitory systems and the neural convergence are phenomena that contribute to this overlapping of conditions in the orofacial region ${ }^{5,6}$.

The orofacial myofunctional disorders (OMD) are defined as any alteration that involves the orofacial muscles generating unfavorable forces to the balance of the stomatognathic system ${ }^{7}$. Some TMD situations present a pain that is triggered or worsened by jaw movements. In this sense, the performance of orofacial functions that respect the functional balance is of utmost importance for a favorable prognostic of its signs and symptoms ${ }^{8,9}$. The concomitant presence of these two clinical conditions (TMD and OMD), although independent, can reveal overlapping signs and symptoms that characterize a challenge for their diagnosis and management.

The objective of this study was, by reporting a clinical case, to present a possible clinical association between painful TMD and the presence of OMD, and to discuss if they can act as complicating factors in TMD management. Moreover, to address the importance of the therapeutic dental management and speech therapy with strategies that involve orofacial myofunctional limits.

\section{CASE REPORT}

Female patient, 35 years, percussionist, complaining about strong joint noises and pain in the orofacial region for 17 years that worsened in the last 3 months. She also reported a strong discomfort with accidental bites that frequently occurred in the cheeks and tongue when chewing and speaking; history of teeth clenching (sleep bruxism) and pain in the shoulders related to her occupational activities. A clinical dental evaluation was conducted. During the occlusal examination, it was noticed a bilateral posterior crossbite and mild dental crowding in the lower anterior region; and in the muscle evaluation, it was observed an intense pain to palpation according to the numerical scale from zero (absence of pain) to 10 (worse possible pain). There were trigger points that reproduced the reported pain (familiar pain) in the masseter and anterior temporal muscles, and localized pain in the temporomandibular joint (TMJ).

The phonological evaluation evidenced severe mandibular rightward deviation when speaking, together with ceceo, interfering in the speech intelligibility and coinciding with the side of the prevalence of spontaneous pain (right). Moreover, other myofunctional disorders were found such as chewing side preference to the right, atypical deglutition, oral-motor incoordination for isolated movements, mandibular rest with no free functional space, and deleterious oral habits. The situation found characterized the diagnosis of OMD.

The TMD diagnosis was carried by an experienced dental surgeon based on the revised protocol Research Diagnostic Criteria for Temporomandibular Disorders (RDC/TMD) ${ }^{10}$ and the phonological by an expert in orofacial kinetics, based on the Orofacial Myofunctional Evaluation Protocol with Scores (AMIO$\mathrm{FE})^{11}$, that allowed to quantify the perceptive evaluation (clinical examination) and compare with the evolution obtained after the therapeutic process. The instrumental evaluation was performed to complement the diagnosis and was composed by surface electromyography (SEMG) and electrovibratography (EVG).

The initial treatment plan included the use of an occlusal splint, speech therapy and directions for self-management. Speech therapy, as previously described ${ }^{12}$, included strategies to eliminate the deleterious oral habits, to self-manage pain (step 1), to coordinate and strengthen the orofacial and masticatory muscles to allow flexible and symmetrical jaw movements, avoiding accidental bites in the cheeks and tongue (step 2-myotherapy) ${ }^{12}$. As the sessions evolved with improvement in the patient's conditions, strategies were included and trained to balance chewing and swallowing and to promote a more intelligible phonoarticulation, in addition to the mandibular rest with free mandibular functional space preserved (step 3 orofacial myofunctional therapy) (Table 1).

After 13 weekly sessions, other 10 sessions were carried for 6 fortnightly sessions and 4 monthly ones, in which were included in the therapeutic process complementary mindfulness practices that constitute an important group of meditation practices used as a tool to reduce stress and anxiety, also being recognized to contribute in the reduction of painful pictures ${ }^{2,13}$. Since the phonological approach was directed to the stomatognathic system, the exercises, guided by the therapist, focused on the rhythm of breathing and attention to the orofacial structures (anchor of the mindfulness practice: aspect or object to which the targeting - or focus - is exercised). The detailed therapeutic plan is shown in table 1 .

Table 2 also shows the data of the clinical evaluations at the initial evaluation and after the treatment. According to the diagnostic criteria of the RDC/TMD, the patient presented myofascial pain without limitation of mouth opening (Ia), and arthralgia (III). The intensity of the overall experience of the initial pain was 9 (visual analog scale, VAS) and after the treatment, it was 2. There was also a reduction of pain on palpation in the masseter, anterior temporal and the TMJ region, which initially was reported with a strong intensity (variation between 8 and 10) 
Table 1. Phonological therapeutic plan: intervention target, objective, management and strategies/actions ${ }^{8}$

\begin{tabular}{lll}
\hline $\begin{array}{l}\text { Intervention } \\
\text { target }\end{array}$ & Objective & Management \\
\hline Pain & $\begin{array}{ll}\text { Pain remission/reduction; } \\
\text { Reduction of related emo- } \\
\text { tional aspects (anxiety) }\end{array}$ & $\begin{array}{l}\text { Self-management } \\
\text { tions direc- }\end{array}$ \\
& &
\end{tabular}

$\begin{array}{ll}\text { Masticatory } & \text { Coordinate/strengthen Mandibular exercises } \\ \text { muscles } & \text { jaw movements }\end{array}$
muscles jaw movements

TMJ

Tongue

Coordinate

Speech

Eliminate ceceos and mandibular deviations

Chewing Balance

Swallowing Eliminate compensations

Keep the functional space free/prevent teeth clenching favor habitual position exercises exercises
Strategies/actions

Thermotherapy for 20 to 30 minutes followed by self-massage, awareness about habits and behaviors that contribute to pain, directions about sleep hygiene and regular physical exercises. 13 we practices focusing breathing and orofacial structures, with the therapist's assistance.

Lower and raise the jaw gently with the support of the apex of the tongue on the hard palate, aiming at a rectilinear motion ( 3 sequences of 10 movements each); gently press a rubber band (latex) of 5 $\mathrm{mm}$ in diameter, placed between the posterior teeth, varying at each bite between premolar and molar teeth ( 3 sequences of 10 bites each), 1 to 3 times a day.

Mandibular exercises as- Mandibular excursive movements for mouth opening, as already sociated with the use of described, right and left laterality, protrusion. (Exercises with octhe occlusal splint clusal splint)

Stimulate the sensitivity, Concomitant mechanical stimulation on the sides of the tongue mobility, increase tension, using toothbrushes, lightly passing the bristles in posteroanterior direction for approximately 15 seconds, repeating 5 times in sequence, with 3 to 5 -second intervals;

Lingual movements to the sides, up and down, slowly, with instruction to touch the apex of the tongue in the labial commissures, in the center of the upper lip and in the center of the lower lip, respectively; Use of the pró-fono" lingual appliance in accordance with the protocol suggested in the instruction manual

Pass the apex of the tongue gently and continuously in back and forth movements for approximately 5 minutes* and then, remain resting keeping this contact of the tongue against the hard palate consciously for an indeterminate time, without the interposition of the tongue between the dental arches (several times per day) ${ }^{\star *}$.

Mandibular exercises, and speech and articulation

Lower and raise the jaw gently with the support of the apex of the tongue on the hard palate, aiming at a rectilinear motion ( 3 sequences of 10 movements each); symmetrically right and left laterality exercise, protrusion exercise trying not to create deviations. (Exercises with occlusal splint); tongue exercises described above; repetition of syllables, words, texts, phonetically balanced with phonemes where the ceceo and mandibular deviations occurred.

Common chewing exercises of different food, consciously, broadening the perceptions about the sensations caused, such as pain, easiness, difficulty, the difference between the sides, physical food characteristics and taste perception; simultaneous bilateral chewing exercise, that is, chewing a portion in each side of the mouth simultaneously. with different food, establish chewing without pain and without aggravating the problem (Mindfulness)

Tongue and swallowing

Tongue exercises described above and swallowing exercises of water and food, with the instruction to position the apex of the tongue opposed to the anterior region of the hard palate, performing a waving movement of the body of the tongue in the anteroposterior direction propelling the food bolus into the pharynx.

Awareness and relaxation, positioning the tongue properly, strengthen the levator muscles of the jaw
Enhance the attention (Mindfulness) in the day-to-day for perception and awareness of the teeth clenching events, using reinforcement strategies as reminders such as self-adhesive notes in different places in the house and at work; gently and countinuously pass the apex of the tongue in back and forth movements for approximately 5 minutes (RLPM) ${ }^{*}$ and then, to rest and counsciously keep this contact of the tongue against the hard palato for an undeterminate time, without the interposition of the tongue between the dental arches (several times per day*; gently press a rubber band (latex) of $5 \mathrm{~mm}$ of diameter, placed between the posterior teeth, varying, at each bite, between the pre-molar and molar teeth ( 3 sequences of 10 bites each), 1 to 3 times per day.

${ }^{*}$ (This exercise was described previously for the relaxation of the levator muscles of the jaw, called lingual-papilla-mandibular reflex (RLPM in Portuguese); ${ }^{8 *}$ (the exercise was also performed with the occlusal splint, that had an orifice for memorization in the palate region corresponding to the one described in table 1$)^{8}$. 
Table 2. Initial and post-treatment results of the intensity of the overall pain experience in the last month (visual analog scale), pain on palpation (VAS), the range of mandibular motion $(\mathrm{mm})$, joint noises and diagnosis according to the Research Diagnostic Criteria for Temporomandibular Disorders (RDC/TMD)

\begin{tabular}{|c|c|c|c|}
\hline \multicolumn{2}{|l|}{ Intensity of the overall pain experience in the last month (VAS) } & $\begin{array}{c}\text { Initial } \\
9\end{array}$ & \multirow{3}{*}{$\begin{array}{c}\text { Post-treatment } \\
2 \\
\text { R-6 /L-8 }\end{array}$} \\
\hline & & & \\
\hline Pain on palpation (VAS) & Masseter & $\mathrm{R}-10 / \mathrm{L}-10$ & \\
\hline & Anterior temporal & $\mathrm{R}-10 / \mathrm{L}-10$ & $\mathrm{R}-6 / \mathrm{L}-4$ \\
\hline & Temporomandibular joint & $\mathrm{R}-8 / \mathrm{L}-10$ & $\mathrm{R}-4$ /L-2 \\
\hline \multirow{4}{*}{$\begin{array}{l}\text { Mandibular movements } \\
(\mathrm{mm})\end{array}$} & Opening & 52 & 45 \\
\hline & R laterality & 8,5 & 10 \\
\hline & L laterality & 10 & 11 \\
\hline & Protrusion & 8 & 7,5 \\
\hline \multirow[t]{3}{*}{ Joint Noises } & Total integral & $\mathrm{R}-45.5 / \mathrm{L}-43.9$ & $\mathrm{R}-4.2 / \mathrm{L}-3.9$ \\
\hline & $>; 300 \mathrm{~Hz}$ & $\mathrm{R}-4.2 / \mathrm{L}-6.3$ & $\mathrm{R}-0.8 / \mathrm{L}-0.5$ \\
\hline & $<300 \mathrm{~Hz}$ & $\mathrm{R}-41.3 / \mathrm{L}-37.6$ & R-3.4/L-3.4 \\
\hline Diagnosis by RDC/TMD & Myofascial pain without mc & ening limitation(l & I arthralgia (IIla). \\
\hline
\end{tabular}

Source: Authors elaboration. $\mathrm{R}$ = right side; $\mathrm{L}=$ left side; $\mathrm{Hz}=\mathrm{Hertz}$ (unit of measure); la and Illa = RDC/TMD categories.

and after the treatment was referred to as a light/moderate pain. With regard to mandibular movements, the mouth opening was trained to reduce its range in order to avoid the eminence crack, which resulted in a variation of 52 to $45 \mathrm{~mm}$. Thus, the intensity of joint noise was reduced, as shown by the EVG.

The electromyographic activity of the anterior temporal and masseter muscles when chewing with raisins was analyzed by the relation between the work side and balance and between the cited muscles. Initially, in the left chewing, there was a greater activity at the work side and the anterior temporal; whereas in the right chewing, the balance side was more active, and the temporal muscles also had greater activity. After the speech therapy for both chewing, the electromyographic activity at the balance side was slightly greater than the work side, and there was a reduction of the temporal muscle activity and an increase in the masseter activity, tending to a better balance (Figure 1).

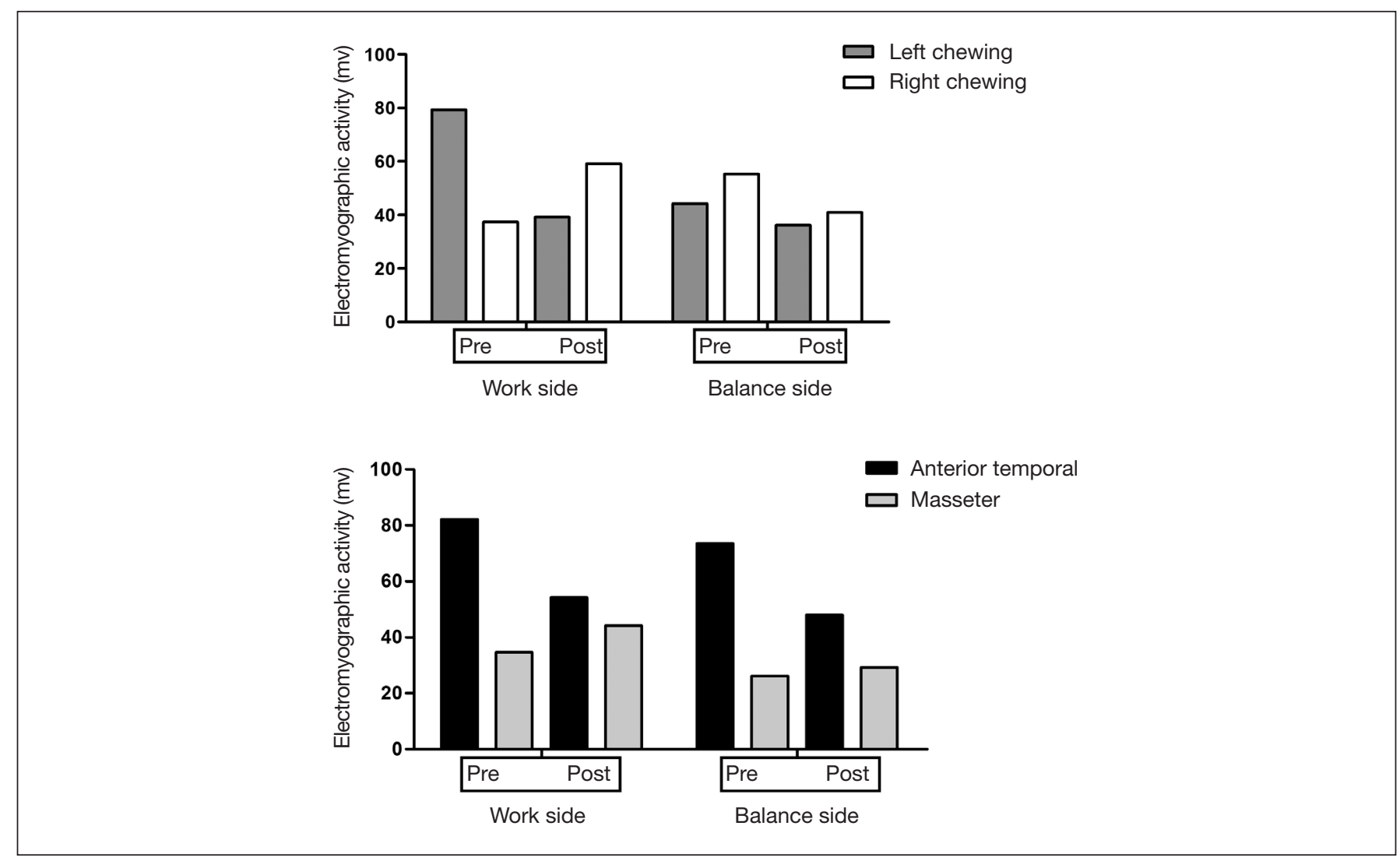

Figure 1. Electromyographic activity in chewing raisins 
The static surface EMG showed that after the treatment there was a reduction in the electric activity of the anterior temporal and masseter muscles in the resting, swallowing, clenching with cotton and clenching in maximum habitual intercuspation (MHI). In addition to a trend of a better balance between the left and right sides, as well as between the pairs of evaluated muscles (Figure 2).
In the initial evaluation, all scores of the AMIOFE protocol were below the cut-off values of normality. After the speech therapy, the scores related to the aspect/posture, mobility, and the total score reached the cut-off of normality. The analysis of the orofacial functions also showed an improvement after the treatment, reaching the standard values of normality (Figure 3).

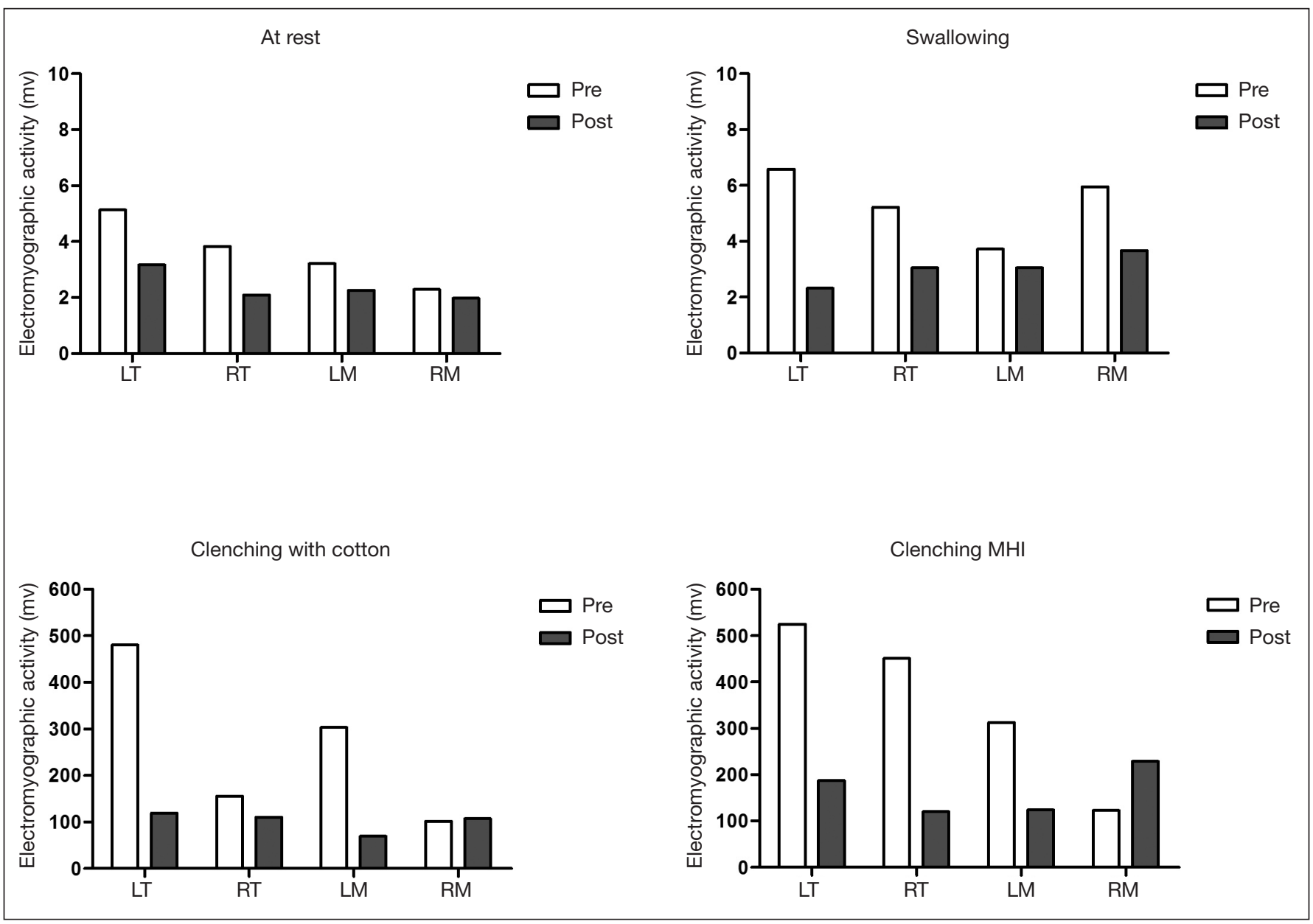

Figure 2. Static electromyography at rest, swallowing, clenching with cotton and clenching in maximum habitual intercuspation MHI = Maximum Habitual Intercuspation; LT = Left Temporal; RT = Right Temporal; LM = Left Masseter; RM = Right Masseter.

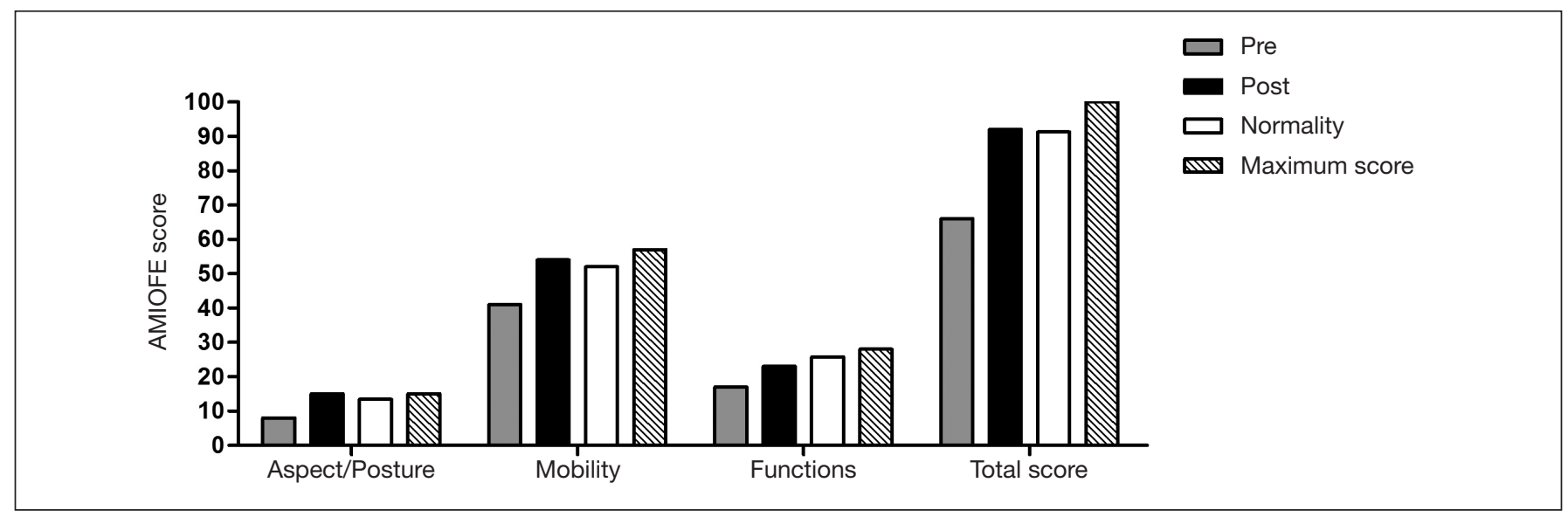

Figure 3. Scores of the orofacial myofunctional evaluation with scores for aspect/posture, mobility, functions and total score 


\section{DISCUSSION}

Painful TMJ treatment approaches are increasingly targeting educational efforts about pain, mandibular exercises, as well as strategies to self-management and to reduce emotional components ${ }^{14}$. The association between exercise treatments, occlusal splint, and self-management instructions favored the new mouth opening range to a functional threshold that does not cause the characteristic noise of the eminence joint, and the expansion of the lateral mandibular movements with better symmetry. Although the TMJ and orofacial pain treatments are no longer totally centered on the occlusal aspects, the occlusal splint is still a good dental tool, either due to the mechanisms of action or because of its cognitive effect and improvement in the emotional aspects ${ }^{15}$.

The identification of joint noises in the TMJ is based on the patient's report and on the palpation examination during the clinical evaluation protocol. The most frequent noises observed are the click and crackle, but other types of noise can be identified, such as the eminence click. This type of click occurs at the end of the mouth opening and/or when the closing starts. It is detected when the condyle-disc complex translates beyond the joint eminence, followed by a change in the position of the jaw. When the mouth opening is limited, it is not possible to identify the eminence click since this type of noise is associated with the wide mouth opening movements ${ }^{16}$. Although frequently found, also in healthy patients, the eminence click is not a clinical diagnosis criterion for TMD, and it is not registered in the most recent diagnosis protocol, the RDC/TMD ${ }^{16}$. However, this can bring great discomfort and impairment of the orofacial functions.

The hyper excursion of the mandibular condyle can reflect a mismatch of the mouth movements and muscle weakness that generates a range of motion higher than the functional need of the individual. Speech therapy is capable of working on the learning of a new neuromuscular position within the functional limits that do not need maximum mandibular movements, preventing the occurrence of joint and eminence noises ${ }^{8}$. The main reason to refer a patient with TMD to an audiologist is the presence of musculoskeletal overload from OMD and parafunctional, or deleterious oral habits. In this sense, the speech therapy proposed for this case was elaborated to reduce the overload on the trigeminal system related to the stomatognathic functions generated by improper muscle compensation acquired by different events over time, and by the deleterious oral habits.

Some speech therapy sessions, mindfulness practices in breathing and orofacial structures were well accepted by the patient with reports of improvement of the sensation of anxiety and increase of the global relaxation. The term mindfulness, refers to a state of constant attention to some object, in order to observe, moment after moment, the variations in that object over time. This object is called an anchor of attention, which can be the rhythm of breathing, body or facial structures for example, where training its focus reduces states of anxiety ${ }^{17}$. This practice, however, was introduced at this moment with the intention of contributing to the conscious perception and execution of orofacial movements and functions, which favors the education about functional capacities and limits. The primary objective was not to reduce the states of anxiety, but it was possible to obtain favorable reports from the patient regarding this aspect, raising the possibility of new investigations that contribute to the inclusion of speech therapy to treat people with TMD.

The scores found for AMIOFE after 23 therapy sessions reached the previously established normal values ${ }^{11}$. This indicates that the speech therapy approach, combined with other dental and selfmanagement modalities, proved to be effective for the orofacial myofunctional balance, and consequently for the reduction of musculoskeletal overload, for the patient's perception and education regarding changes in myofunctional habits and behaviors and therefore contributing to the treatment/management of TMD in the way recommended by the current literature.

The number of speech therapy sessions was higher than that reported in the literature, which is usually a total of 12 or 13 sessions $^{18,19}$. In this case, the OMD presented important aspects related to TMD such as marked mandibular deviations during speech with exaggerated ceceo, swallowing with many cervical and tongue compensations, mandibular rest without free functional space, that is, in a state of teeth clenching with the tongue compressed most of the time; in some moments with the tongue interposed between the arches, causing strong marks on its sides. The difficulty to install and automate myofunctional patterns that favor the balance of the stomatognathic system led to a higher number of therapeutic sessions, which was possible due to the patient's compliance with the proposed schedule. Experts in the field of orofacial motricity claim that OMD may not be the cause of TMD, but the more severe the OMD, more difficult its resolution without approaches that specifically target myofunctional orofacial re-education or rebalancing ${ }^{8}$.

The presence of comorbidities can be one complication or nonresolution factors of TMD after treatment, that is, another problem that may occur in parallel with what is being treated, that has some relation and influence on its severity ${ }^{2,3,20,21}$. In this case, it seems that the OMD was a TMD comorbidity since we cannot claim that it was the triggering factor, but its presence contributed to the aggravation and maintenance of TMD. Rebalancing the altered orofacial myofunctional aspects, in association with the other therapeutic modalities, contributed to the TMD resolution, limiting the mandibular movements, reducing orofacial pain, and remission of the pain referred on palpation, reducing joint clicks and their intensity.

These results also produced a lower and more balanced electromyographic activity of the masseter and anterior temporal muscles in the tests at rest, swallowing and maximum teeth clenching (maximum voluntary contraction). Some studies have shown an increase in activity for evidence of high demand for muscle contraction after treatment and a decrease for tests of low demand, such as rest and swallowing ${ }^{8,11}$. In this case, lowering the electromyographic activity may have occurred due to excessive patient care when clenching the teeth since it was a much-discussed aspect during the treatment. However, more important than increasing or decreasing the activity was to address the balance between the pairs of muscles and between the sides. This can be observed in the electromyographic examination during the masticatory function of raisins, in which changes with a trend 
to the balance between the work and balancing sides and the decrease of the activity of the anterior temporal muscles, quite similar to the activity of the masseters. After the time spent to achieve the myofunctional balance, we concluded that the electromyographic results were satisfactory for this case, constituting its individual limit $^{8}$.

\section{CONCLUSION}

Managing OMD together with dental and self-management therapies is essential not only for the improvement of pain but also to modify the functional condition to achieve the balance of the stomatognathic system, specific to each clinical case of painful TMD. In this sense, it is worth mentioning the importance of dental and speech interventions in patients with orofacial myofunctional disorders as possible comorbidity to painful temporomandibular dysfunction.

\section{REFERENCES}

1. Slade GD, Ohrbach R, Greenspan JD, Fillingim RB, Bair E, Sanders AE, et al. Painful temporomandibular disorder: decade of discovery from OPPERA studies. J Dent Res. 2016;95(10):1084-92.

2. Ohrbach R, Dworkin SF. The evolution of TMD diagnosis: past, present, future. J Dent Res. 2016;95(10):1093-101.

3. Manfredini D, Winocur E, Ahlberg J, Guarda-Nardini L, Lobbezoo F. Psychosocial impairment in temporomandibular disorders patients. RDC/TMD axis II findings from a multicentre study. J Dent. 2010;38(10):765-72.

4. Scrivani SJ, Keith DA, Kaban LB. Temporomandibular disorders. N Engl J Med. 2008;359(25):2693-705.

5. Campi LB, Jordani PC, Tenan HL, Camparis CM, Gonçalves DA. Painful temporomandibular disorders and central sensitization: implications for management-a pilot study. Int J Oral Maxillofac Surg. 2017;46(1):104-10.

6. Costa YM, Conti PC, de Faria FA, Bonjardim LR. Temporomandibular disorders and painful comorbidities: clinical association and underlying mechanisms. Oral Surg Oral Med Oral Pathol Oral Radiol. 2017;123(3):288-97.

7. Pereira CC, De Felício CM. Os distúrbios miofuncionais orofaciais na literatura odontológica: revisão crítica. Rev Dent Press Ortodon Ortop Facial. 2005;10(4):134-42.
8. de Felício CM, de Oliveira MM, da Silva MA. Effects of orofacial myofunctional therapy on temporomandibular disorders. Cranio. 2010;28(4):249-59.

9. Ferreira CL, Machado BC, Borges CG, Rodrigues Da Silva MA, Sforza C, De Felício CM. Impaired orofacial motor functions on chronic temporomandibular disorders. J Electromyogr Kinesiol. 2014;24(4):565-71.

10. Look JO, Schiffman EL, Truelove EL, Ahmad M. Reliability and validity of Axis I of the Research Diagnostic Criteria for Temporomandibular Disorders (RDC/TMD) with proposed revisions. J Oral Rehabil. 2010;37(10):744-59.

11. de Felício CM, Medeiros AP, Melchior MO. Validity of the 'protocol of oro-facial myofunctional evaluation with scores' for young and adult subjects. J Oral Rehabil. 2012;39(10):744-53.

12. Melchior MO, Machado BC, Magri LV, Mazzetto MO. Effect of speech-language therapy after low-level laser therapy in patients with TMD: a descriptive study. Codas. 2016;28(6):818-22.

13. Slade GD, Fillingim RB, Sanders AE, Bair E, Greenspan JD, Ohrbach R, et al Summary of findings from the OPPERA prospective cohort study of incidence of first-onset temporomandibular disorder: implications and future directions. J Pain. 2013;14(12 Suppl):T116-24.

14. Michelotti A, Iodice G, Vollaro S, Steenks MH, Farella M. Evaluation of the shortterm effectiveness of education versus an occlusal splint for the treatment of myofascial pain of the jaw muscles. J Am Dent Assoc. 2012;143(1):47-53

15. Costa YM, Porporatti AL, Stuginski-Barbosa J, Bonjardim LR, Conti PC. Additional effect of occlusal splints on the improvement of psychological aspects in temporomandibular disorder subjects: A randomized controlled trial. Arch Oral Biol. 2015;60(5):738-44.

16. Schiffman E, Ohrbach R, Truelove E, Look J, Anderson G, Goulet JP, et al. International RDC/TMD Consortium Network, International Association for Dental Research; Orofacial Pain Special Interest Group, International Association for the Study of Pain. Diagnostic Criteria for Temporomandibular Disorders (DC/TMD) for Clini$\mathrm{cal}$ and Research Applications: recommendations of theInternational RDC/TMD Consortium Network* and Orofacial Pain Special Interest Group †. J Oral Facial Pain Headache. 2014;28(1):6-27.

17. Kabat-Zinn J. An outpatient program in behavioral medicine for chronic pain patients based on the practice of mindfulness meditation: theoretical considerations and preliminary results. Gen Hosp Psychiatry. 1982;4(1):33-47.

18. de Felicio CM, Melchior Mde O, Da Silva MA. Clinical validity of the protocol for multi-professional centers for the determination of signs and symptoms of temporomandibular disorders. Part II. Cranio. 2009;27(1):62-7.

19. Machado BC, Mazzetto MO, Da Silva MA, de Felício CM. Effects of oral moto exercises and laser therapy on chronic temporomandibular disorders: a randomized study with follow-up. Lasers Med Sci. 2016;31(5):945-54.

20. Visscher CM, Van Wesemael-Suijkerbuijk EA, Lobbezoo F. Is the experience of pain in patients with temporomandibular disorder associated with the presence of comorbidity? Eur J Oral Sci. 2016;124(5):459-64.

21. Manfredini D, Ahlberg J, Winocur E, Guarda-Nardini L, Lobbezoo F. Correlation of RDC/TMD axis I diagnoses and axis II pain-related disability. A multicenter study. Clin Oral Investig. 2011;15(5):749-56. 